\title{
SEED CHARACTERISTICS AND ASYMBIOTIC GERMINATION OF GALEANDRA BATEMANII ROLFE AND G. GREENWOODIANA WARFORD
}

\author{
Marilyn H.S. Light ${ }^{1} \&$ Michael MacConaill \\ ${ }^{1}$ Author for correspondence: 174 Jolicoeur St., Hull, Québec, Canada J8Z 1C9. mlight@igs.net
}

The genus Galeandra Lindl. is a member of subtribe Cyrtopodiinae (Dressler 1993). It is represented in the Americas, from Florida through Mexico and Central America and as far south as Argentina. In Mexico, suitable habitat of Galeandra batemanii Rolfe and of Galeandra greenwoodiana Warford is sparse, patchy and widely separated with sites $300 \mathrm{~km}$ or more apart (Warford 1994). Galeandra batemanii has been reported to be occasionally lithophytic (Pollard 1974).

The plant of $G$. batemanii represented in this study, O. Suarez 1122 (sub W-594), was collected in an area of the Gulf slope of Oaxaca, Mexico, east of the Continental Divide, at $750 \mathrm{~m}$ elevation where it was found by Octavio Suarez and Ed Greenwood in 1989, growing on a rotting pine trunk lying on the ground and overhanging a road in a small pine savannah within moist tropical forest (E. W. Greenwood, pers. comm.). Galeandra batemanii is rare in Mexico (Warford 1994) and may now be extinct. The three plants of G. greenwoodiana represented in this study, $W-542, W-543$ and $W-544$, were found growing on the Sabal palm (Sabal rosei) in Nayarit, Mexico, elevation $300 \mathrm{~m}$, under hot, seasonally dry conditions (Warford 1994). This population is now extirpated (Warford, pers. comm.). According to Warford, G. greenwoodiana is generally more robust than G. bate manii.

This investigation was undertaken as a study of germination behaviour. The species were rare, which in itself was a stimulus to gather as much data as possible from the limited material at hand. When we began this study, we were also involved in parallel investigations of the germination behaviour of Cypripedium parviflorum Salisb. var. pubescens (Willd.) Knight and of Epipactis helleborine (L.) Crantz (Light \& MacConaill 1998). We observed germination polymorphism in E. helleborine (Light 1995), and in particular, our observation that the production of a particular seed class varied with habitat and seed parent status, caused us to look more closely at the seeds and seedling behaviour in the Galeandra specimens.
Materials and methods. Two capsules (GbA and $\mathrm{GbB}$ ) were obtained through hand self-pollination of flowers on two inflorescences arising from separate shoots of the same plant of G. batemanii. Capsule GbA came from the smaller of the two shoots. A third capsule (Gg1) was obtained through hand pollination of $G$. greenwoodiana $\mathrm{W}-544$ with pollen from $\mathrm{W}-543$, while two further capsules ( $\mathrm{Gg} 2$ and hybrid) were obtained through hand pollination of two flowers of the same inflorescence of $G$. greenwoodiana W-543 with pollen from W-542 and from $G$. batemanii respectively.

All of these plants had been maintained in cultivation in Puerto Vallarta, Mexico, for at least six months before pollination. When the capsules naturally dehisced, seeds were harvested then forwarded to the investigators by airmail. Seeds were subsequently stored at $4{ }^{\circ} \mathrm{C}$ in a frost-free refrigerator which maintained a relative humidity of $28 \%$.

Seed and embryo length and width in samples of 30 seeds from each seed lot were measured using an optical micrometer and a 10x objective.

Replicates of approximately 100 seeds were sown on $15 \mathrm{ml}$ slants in $25 \times 150 \mathrm{~mm}$ test tubes. All slants were incubated at $22 \pm 2{ }^{\circ} \mathrm{C}$ with the slant surface horizontal. Illumination, when used, was by a pair of 40 W Gro \& Sho (Canadian General Electric) wide spectrum fluorescent lamps $\left(300 \mu \mathrm{mol} \cdot \mathrm{m}^{-2} \cdot \mathrm{sec}^{-1}\right), 30 \mathrm{~cm}$ above the test tubes with a 16 hour photoperiod. All slants were examined with a hand lens immediately after sowing to count the number of seeds containing embryos before incubation began. Polyembryony was assessed both from the sown seeds and from examination of a further 200 seeds from each seed batch.

Germination Assessment. The slants were examined weekly for germination (rupture of the testa). The final count of seeds germinated was obtained 21 days after sowing as the growth of protocorms and rhizoids thereafter made accurate counts difficult. Those replicates being incubated in darkness were exposed to approximately ten minutes of incandescent light each time ger- 
mination was assessed. Replicates contaminated by fungal growth were excluded from the final assessment.

Replating Protocorms. Three-week-old protocorms were transplanted onto the relevant replate medium (50 $\mathrm{ml}$ per $500 \mathrm{ml}$ flask, 15 protocorms per flask, three flasks per sample). Stoppers were vented through a single hole plugged with cotton wool and covered on the outside with Sun Cap Closures (Sigma Chemical Co.). Seedlings were grown at $22 \pm 2{ }^{\circ} \mathrm{C}$. Illumination was as previously described.

Experiment 1 (started July 1991). Seeds were surfacesterilized by shaking for ten minutes in a 1:20 commercial bleach solution (final concentration was $0.25 \%$ available chlorine) then rinsed once with sterile deionized water and sown on G\&B Mother Flask Medium V (G\&B Orchid Laboratories, Vista, CA), adjusted to $\mathrm{pH}$ 5.8 before sterilization. Four replicates of each seed lot were incubated in darkness, and five with illumination. The resulting protocorms were transplanted onto $G \& B$ Replate Medium V (G\&B Orchid Laboratories, Vista, $\mathrm{CA})$, prepared according to manufacturer's instructions.

Experiment 2 (started January, 1992). Because we had had problems with fungal contamination of one seed lot and wished to replicate the experiment on a defined medium, we conducted a second experiment in which a 1:10 bleach solution $(0.5 \%$ available chlorine) was used to surface sterilize the seed. Seeds were then sown on Phytamax $®$ Orchid Maintenance Medium P6668 (Sigma Chemical Co.) with $8 \mathrm{~g} / \mathrm{L}$ agar (Difco) added, adjusted to $\mathrm{pH} 5.8$ before sterilization. Five replicates of each lot were incubated in darkness, and five with illumination. The resulting protocorms were transplanted onto the same medium.

Seedling Measurement. Measurement of seedlings raised on G\&B Replate Medium V was not practicable because of protocorm proliferation. Seedlings grew normally on Phytamax ${ }^{\circledR}$ P6668 medium. One randomly selected flask representing each seed lot was chosen for seedling measurement when the first pseudobulbs matured and the plantlets were about to enter the deciduous phase, approximately nine months after sowing. The length and diameter of the pseudobulbs of ten seedlings were measured using a Vernier caliper, while the length and width of the longest leaf of each seedling was measured using a ruler. Volumes of embryos and pseudobulbs were estimated (as $\pi \mathrm{ld}^{2} / 6$ ) on the assumption of prolate ellipsoidal geometry.

Results and discussion. Capsule Dehiscence. The two capsules of G. batemanii dehisced at 316 days (GbA) and 342 days (GbB) respectively: two capsules of $G$. greenwoodiana, at $279(\mathrm{Gg} 2)$ and $286(\mathrm{Gg} 1)$ days, and the capsule of the interspecific hybrid at 282 days. This suggests an interspecific difference in time to dehiscence although more data from additional specimens would be needed for confirmation.

The external appearance of all seeds examined was similar. The testa was about five cells long: cell surfaces were conspicuously thickened longitudinally. Seed dimensions of $G$. batemanii, G. greenwoodiana, and their interspecific hybrid showed no consistent overall pattern. There was no meaningful difference in seed length between seed lots, while embryo lengths segregated into two groups with no species-related pattern detectable. On the other hand, seed and embryo widths, and estimated embryo volume, showed a common clear separation between samples from the two seed lots having G. greenwoodiana $\mathrm{W}-543$ as a seed parent $(\mathrm{Gg} 2$ and the hybrid) and those from the other three lots.

Seeds of G. batemanii and of G. greenwoodiana had filamentous suspensors consisting of one or two large basal cells with conspicuous granules and a two to fivecelled filamentous distal region oriented towards the micropylar end of the seed. The suspensor and embryo were contained within the outer integument. Seeds having G. greenwoodiana (W-543) as a seed parent had folded or bent suspensor filaments. In all other seed lots, the suspensor was straight. We observed swelling of suspensor cells during imbibition, coincident with swelling of the embryo in the first stages of germination of all seed lots suggesting that there may be a passive role in water absorption for the suspensor (Fig. 1). All samples of G. batemanii and G. greenwoodiana had some polyembryonic seeds, but the incidence of polyembryony was low. The most frequent form of polyembryony observed was diembryony: two examples of seeds with three embryos were noted during seed measurement. Variability between samples of the incidence of polyembryony within capsules was within expected limits. The incidence of polyembryony in seed lot GbB was significantly greater than in any of the other four seed lots.

Polyembryony is relatively common in relatives of Galeandra (M.A. Clements, pers. comm.). Seeds of Galeandra and of other genera of this subtribe have a particular type of suspensor which has been shown to have an active role in nutrient transfer from the main body of the outer integument cells to the embryo during seed development (Clements 1995). The suspensor generally becomes nonfunctional as the embryo 
matures. Suspensor cells have a primary cell wall which is likely to provide a site for water uptake (E.C. Yeung, pers. comm.).

Seed Storage Conditions. Once we had received the seed, it was stored under standard conditions. Harvest to receipt interval ranged from 7 to 45 days. Six months refrigeration did not appear to affect seed germination as it was essentially the same in darkness in Experiments 1 and 2.

Seed Pretreatment. Seeds of all samples turned bright yellow orange when first exposed to bleach then became paler as the treatment progressed. Treatment with the more concentrated bleach solution ( $0.5 \%$ active chlorine) for ten minutes in Experiment 2 reduced fungal contamination to manageable levels. This bleach treatment did not reduce seed germination.

Germination in the Dark. All samples from a given seed lot germinated to the same extent on both media when incubated in darkness. Although all replicates of one seed lot of G. batemanii (GbA), were lost to seedborne fungal contamination in Experiment 1, the other results in Experiment 2 so closely paralleled those of Experiment 1 that the effect of medium could be assumed to have been negligible. Seeds from G. greenwoodiana and the hybrid had an average $85 \%$ germination, while germination was much less for seeds from G. batemanii, being $49 \%$ for seed lot GbA and only $28 \%$ for GbB.

Germination and Protocorm Development with Illumination. Incubation with illumination significantly increased the germination of seeds from G. batemanii, while it had a minor inhibitory effect on germination of seed from G. greenwoodiana and the hybrid, the effect being most marked for seed lot Gg2. Seeds sown on Phytamax ${ }^{\circledR}$ P6668 showed significantly higher germination with illumination than those sown on G\&B V medium, with the exception of those from seed lot $\mathrm{Gg} 1$. With G. batemanii, germination of seed lot GbA with illumination on Phytamax® P6688 averaged 96\%. Under the same conditions, germination of seed lot $\mathrm{GbB}$ was only $60 \%$, although this was still greater than the $28 \%$ in the dark or the $39 \%$ on G\&B V medium with illumination. Protocorm rhizoids began forming approximately two weeks after germination. Exposure to light moderately inhibited rhizoid development in all samples.

The concept of variable germination response to light is not new (Stoutamire 1964). Seeds of many terrestrial orchids are known to germinate better in darkness than in the light (Rasmussen 1995). Rasmussen et al. (1990)

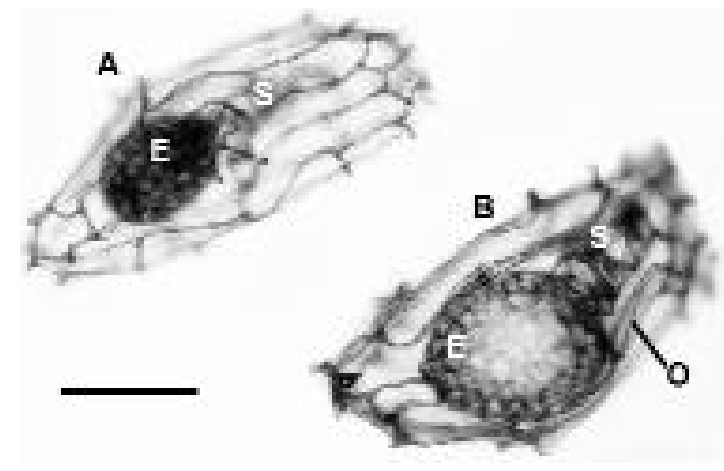

Fig 1. Seeds of Galeandra greenwoodiana W-542 (Gg2) $48 \mathrm{~h}$ after sowing showing: (A) an embryo which has not imbibed and may not germinate; and (B) an imbibed, swollen embryo and suspensor. Symbols: E embryo; S - suspensor; O - outer integument. All samples were stained with Trypan Blue, $0.2 \%$ in $45 \%$ acetic acid, for 30 seconds to improve contrast and visualization of seed components, then rinsed, and mounted in water. Scale bar: $100 \mu \mathrm{m}$.

reported that in the European terrestrial orchid, Dactylorhiza majalis, about 14 days of incubation in darkness were required for a normal germination percentage. Rasmussen \& Rasmussen (1991) suggested that lightmediated inhibition in $D$. majalis would reduce the risk of dessication after germination: seeds would have to be within the soil and away from light to germinate. They further observed that while seeds of D. majalis have an initial light sensitive phase, light inhibition was not complete: a small percentage of seeds could germinate without darkness. Zettler \& Hofer (1997) have suggested that even closely related species may differ in their response to light during germination. Control of germination rate and of rhizoid development of seeds not yet within dark and moist surroundings could be especially critical to orchids whose habitat is seasonally harsh and dry as with $G$. greenwoodiana. Dessication-sensitive rhizoids are conduits connecting intracellular mycorrhizal hyphae to the medium (Rasmussen 1990, Oddie et al. 1994). One assumes that seeds of epiphytic orchids, like those of terrestrial species, must lodge in some suitable niche where conditions support the germination process and where mycorrhizal infection can occur.

Seedling Growth. Germinating seeds were replated three weeks after sowing before rhizoids became matted: once rhizoids have formed they may become tangled thus making it almost impossible to replate without some damage to protocorms and their rhizoids. Rather than developing normally, protocorms trans- 
planted to G\&B Replate Medium V formed poorly differentiated tissue masses. Seedling measurement was therefore not possible and so work with this medium was abandoned. Seedling growth and development proceeded normally on Phytamax ${ }^{\circledR}$ P6668 medium. Clear size differences were seen in seedlings from the different seed lots. Seedlings from seed lot GbA consistently developed long narrow leaves, whereas the leaves of seedlings from the other seed lots were broader and more variable in length. Pseudobulb shape as characterized by length/width ratio was clustered in three groups: G. greenwoodiana ( $\mathrm{Gg} 1$ and $\mathrm{Gg} 2)$; G. batemanii $(\mathrm{GbA})$ and the hybrid; and G. batemanii (GbB), the last being the most elongated. Pseudobulb sizes also formed three groups, whether measured by length, diameter or estimated volume: those of seedlings from the hybrid and from seed lot GbB were the largest, those of the two seed lots from G. greenwoodiana were somewhat smaller, while those from seed lot GbA were much smaller. The two capsules produced by self-pollination of $G$. batemanii differed significantly in germination and in seedling behaviour. While seeds of GbA germinated better than those of GbB, seedlings of GbA had the smaller pseudobulbs. Seedlings of GbB more closely resembled those of the intraspecific hybrid in dimensions, whereas seedlings of GbA were outliers.

Why such differences? Post-harvest transit and storage conditions could affect seed germinability but could not influence seed dimensions or the degree of polyembryony, and would be highly unlikely to affect ultimate seedling dimensions. Seed parent resource limitations could possibly have affected seed development in capsule GbA which was produced by the smaller shoot. While we have no explanation for the disparity between GbA and GbB, significant withinplant variation shows a need for caution when interpreting data where sample size is small.

\section{LiTERATURE Cited}

Clements, M.A. 1995. Reproductive biology in relation to phylogeny of the Orchidaceae especially the Tribe Diurideae. Ph.D. Dissertation. Australian National University, Canberra, Australia.

Dressler, R.L. 1993. Phylogeny and Classification of the Orchid Family. Dioscorides Press, Portland, Oregon. 314 pp.

Light, M.H.S. 1995. Germinating seeds of Epipactis helle borine. Orchid Rev. 103: 267-269.

Light, M.H.S. and M. MacConaill. 1998. Factors affecting germinable seed yield in Cypripedium calceolus var. pubescens (Willd.) Correll and Epipactis helleborine (L.) Crantz (Orchidaceae). Bot. J. Linn. Soc. 126: 3-26.

Oddie, R.L.A., K.W. Dixon, and J.A. McComb. 1994. Influence of substrate on asymbiotic and symbiotic in vitro germination and seedling growth of two Australian terrestrial orchids. Lindleyana 9: 183-189.

Pollard, G. E. 1974. The genus Galeandra in Mexico. Orquídea (Méx) 4: 168-171.

Rasmussen, H.N. 1990. Cell differentiation and mycorrhizal infection in Dactylorhiza majalis (Rchb.f). Hunt \& Summerh. (Orchidaceae) during germination in vitro. New Phytol. 116:137-148.

Rasmussen, H.N. 1995. Terrestrial Orchids: From Seed to Mycotrophic Plant. Cambridge University Press, Cambridge.

Rasmussen, H.N., T.F. Andersen and B. Johansen. 1990. Temperature sensitivity of in vitro germination and seedling development of Dactylorhiza majalis (Orchidaceae) with and without a mycorrhizal fungus. Pl. Cell Environ. 13: 171-177.

Rasmussen, H.N. and F.N. Rasmussen. 1991. Climatic and seasonal regulation of seed plant establishment in Dactylorhiza majalis inferred from symbiotic experiments in vitro. Lindleyana 6: 221-227.

Stoutamire, W. P. 1964. Seeds and Seedlings of Native Orchids. Michigan Bot. 3: 107 - 119.

Warford, N. 1994. The Mexican Galeandras (Orchidaceae) Lindleyana 9: 39-49.

Zettler, L. W. and C. J. Hofer. 1997. Sensitivity of Spiranthes odorata seeds to light during in vitro symbiotic seed germination. Lindleyana 12:26-29.

Marilyn Light was born in Montréal, Québec, Canada, receiving her post-secondary education in Agriculture and Microbiology at McGill University. She subsequently taught botany in Barbados, West Indies and it was there, in 1970, that she began studying orchids. She moved back to Canada where she joined the staff of the Professional Training Service, University of Ottawa and soon began the first of several long term on-going studies of wild Canadian orchid populations. She has received the Anne Hanes Conservation Award from the Ottawa Field-Naturalists Club for her work. In 2000, she received the highest award of the Ontario Horticultural Association, the Silver Medal Award, for her vision and achievements in horticulture. Marilyn Light is Chairman of the Canadian Orchid Congress Conservation Committee, and of the North American Region and the Education Committees of the Orchid Specialist Group.

Michael MacConaill is a retired Professor of Pharmacology, Faculty of Medicine, University of Ottawa, with an interest in statistics and photography. 